\title{
Rock Slope Stability Problem Modeling and Remediation of the Arabian Shield Rocks: A Case Study From Werka Descent Road West of Saudi Arabia
}

\author{
Bahaaeldin Sadagah* $^{*}$
}

King Abdulaziz University, P.O. Box 80099, Jeddah 21589, Saudi Arabia

\begin{abstract}
Werka descent road lies at western region of Saudi Arabia. The slope faces get damaged due to rainstorm and absence of remedial measures. Werka mountainous road is subjected to failures of man-made rock slope faces, along both sides of $8-\mathrm{m}$ wide road. Intensive geotechnical study includes the application of RMR and GSI rock mass classification system which indicates that the rocks are of medium to poor quality. The integrated techniques such as graphical method, modeling, and simulation were utilized to assess rock slope failures by using DIPS, RocPlane and Swedge programs, and the remedial measures for failures were recommended. Debris flows from higher elevation were a result of the weathering process and poor rock quality. A manmade slope cut was studied and modeled utilizing the integrated techniques. The analyses indicate that the intensity of rainfall, joint sets attitudes, slope face attitudes, $\mathrm{J}_{\mathrm{v}}$, block size, block shape, and specific gravity are the main factors in rock slope failure problems.
\end{abstract}

Keywords: Rock slope instability, plane failure, wedge failure.

\section{INTRODUCTION}

The urbanization and development strategy of the government of the Kingdom of Saudi Arabia is basically grounded on the construction of modern roads and highways network. Furthermore, a great deal of attention has been given to construct a number of descent roads, where road cuts and bridges as well as tunnels through the higher mountains in these descents have been planned to construct. These descent roads play a vital role in connecting the various parts of the Kingdom together, and provide the ease of transportation. Such routes connect the Red Sea coastal plain to the west with the high-rising mountains at the east.

These descent roads, especially those across areas of various topography of high relief being similar to those in the western and southern parts of the country, are currently suffering from common landslides of various scales.

Engineering projects often require the excavation of the rock cuts that must be safe for large-scale slope instability, during both construction and operation stages. An example of the difficult descent is under investigation of this research study. Many rock slope failures and other forms of geohazards locate at Tabuk governate roads, one of these roads lies at the south west corner of Tabuk governate, which is locally known as Werka descent (Fig. 1).

The geographic location and topography of the whole study area at Al-Wajh quadrangle, Tabuk governate are shown in (Figs. 2, 3). Werka descent 8-meter wide road which was constructed in 2008 north of the Kingdom is

*Address correspondence to this author at the King Abdulaziz University, P.O.Box 80099, Jeddah 21589, Saudi Arabia; Tel: 00966505669519; Fax: 00966-12-2522970; E-mails: bsadagah@yahoo.com, sadagah@gmail.com frequently subjected to rock slopes failures especially during rainy seasons in the recent years. The GPS technology has been used to trace Werka descent road alignment and plot it on the Google earth image (Fig. 3). The specific road alignment location starts at $26^{\circ} 10^{\prime} 3.53^{\prime \prime} \mathrm{N}$ and $37^{\circ} 24^{\prime}$ $1.77^{\prime \prime} \mathrm{E}$ and ends at $26^{\circ} 10^{\prime} 45.28 \mathrm{~N}$ and $37^{\circ} 23^{\prime}$ '5.96”.

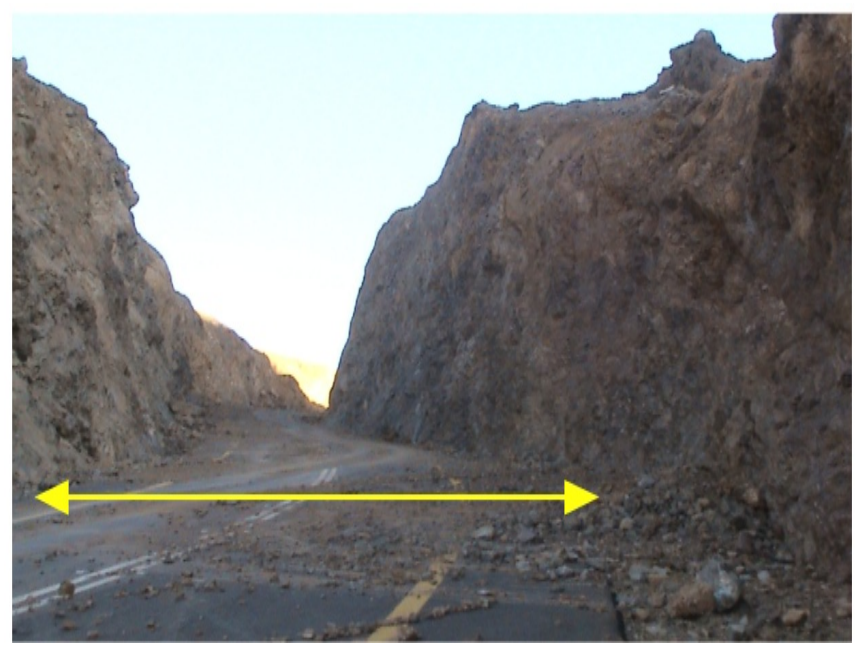

Fig. (1). Werka descent 8 meter road, at Alkharar town, Tabuk governate.

\section{BRIEF GEOLOGY}

The whole study area in general lies at southeast corner of Al-Wahj quadrangle, in the northwestern Al Hijaz mountain range between latitudes $26^{\circ} 00^{\prime} \mathrm{N}$ and $27^{\circ} 00^{\prime} \mathrm{N}$, and longitudes $36^{\circ} 00^{\prime} \mathrm{E}$ and $37^{\circ} 30^{\prime} \mathrm{E}$. The rock masses are underlain by late Precambrian rocks. The Arabian Shield consists of folded, metamorphic plutonic and stratified rocks. 
The Precambrian lithostratigraphic succession of the AlWajh quadrangle is explained by Bryan Davies [1]. The study area of Werka descent lies at Hajr formation, the oldest unit of Bayda group.

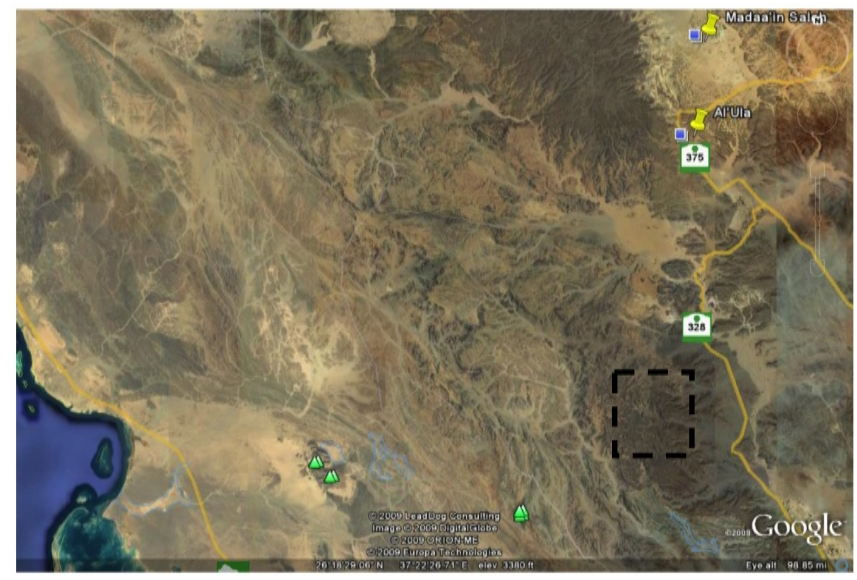

Fig: (2). Satellite image shows the location of the whole study area at Al-Wajh quadrangle, the dashed rectangle.

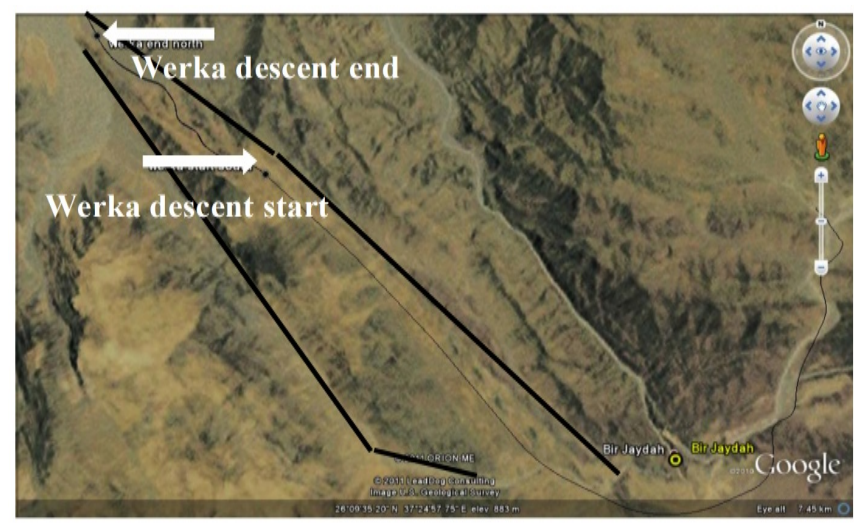

Fig. (3). Location of the Werka descent is shown on Google Earth image. The black thin line is the present road in the study area, and the black thick line represents the faults.

\section{Metamorphism}

Most of the Precambrian rocks of the quadrangle were regionally metamorphosed to the low and middle greenschist facies. However, amphibolite-grade metamorphism took place in some complexes, zones and groups. Most of the rocks along Werka descent road are altered to chlorite and clays.

\section{Structural Geology}

Two phases of major folding have been recognized in the quadrangle. The first-phase folds are low-dipping axial surfaces striking about $90^{\circ} \mathrm{E}$. The second-phase folds have variably dipping axial surfaces striking between $\mathrm{N} 45^{\circ} \mathrm{S}$ and $\mathrm{N} 70^{\circ} \mathrm{W}$, which affect Werka descent.

In the southeast corner of the quadrangle, major faults exist with strikes ranging from $\mathrm{N} 80^{\circ} \mathrm{W}$ to $\mathrm{N} 45^{\circ} \mathrm{W}$ which extend into the zone of Najd faults that trend about $\mathrm{N} 45^{\circ} \mathrm{W}$ across the Precambrian shield of northern Arabia [2-4].
The rocks at Werka descent lie between two faults striking between $\mathrm{N} 45^{\circ} \mathrm{S}$ and $\mathrm{N} 70^{\circ} \mathrm{W}$. A number of minor faults (Fig. 3) are located in the area at small and micro scale. Faults strikes are in the same direction of major faults in the quadrangle between $\mathrm{N} 45^{\circ} \mathrm{S}$ and $\mathrm{N} 70^{\circ} \mathrm{W}$. Schistosity direction of the rocks has the faults attitudes. Folds strikes are taking the same directions as faults.

\section{ROCK MASSES QUALITY}

The rock slope under investigation is a part of Werka descent road. It is about $200 \mathrm{~m}$ long. The rock masses at this station are rigid and altered. The rock masses are metabasalt dry to dump, and are of medium to poor quality after corrections, according to $R M R$ classification system [5]. The technical properties of the rocks are as follows: the joints friction angle $=34^{\circ}$, the rock material $=2.76 \mathrm{~kg} / \mathrm{m}^{3}$, compressive strength $=72 \mathrm{MPa}$, medium to highly weathered, $R Q D=82$ in general, joint spacing $=5.26 \mathrm{j} / \mathrm{m}$, block size $=0.04 \mathrm{~m}^{3}, R M R=34$, i.e. poor rock mass quality, $G S I=15$ to $35[6-8]$.

The rock slope along the road cut at slope angle $85^{\circ}$ and $7 \mathrm{~m}$ height, suffers from frequent failures on the road, mainly in rainy seasons (October to April). No support measures were taken at the site (Fig. 4).

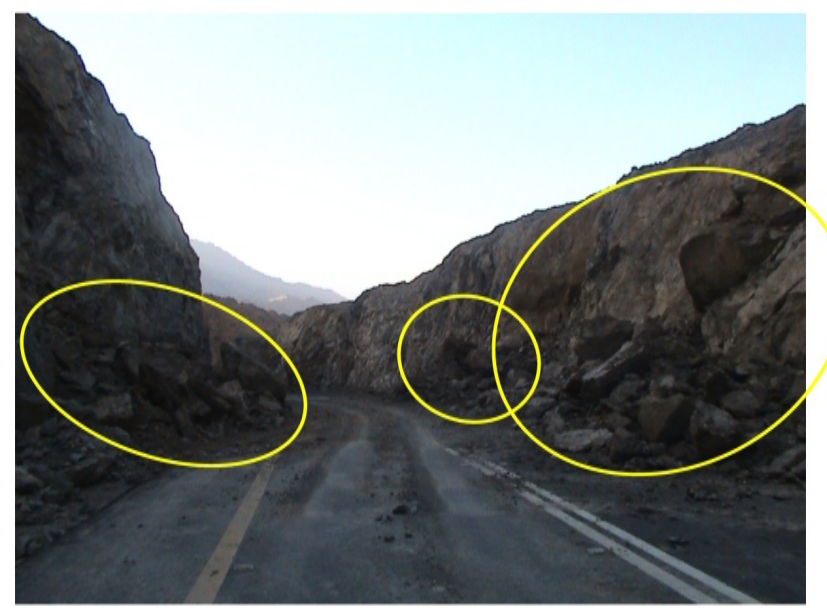

Fig. (4). Rock slope failures shown at yellow circles at the northeast (right) and southwest (left) slope face cuts. Rock blocks were removed aside after the rainfall to clear the road.

The graphical method [9] shows that the factor of safety is critical along man-made slopes. The stereonet made (Fig. 5) using DIPS software [10] shows that the friction angles at dry and wet seasons are $35^{\circ}$ and $25^{\circ}$, respectively.

In addition to the rock slope instability, such slope cut suffers from many events of rockfalls originated from upper slope elevations, which are potentially source areas causing problems to the road commuters and vehicles.

\section{ROCK SLOPES MODELING}

Location of the stations along the Werka descent is traced by the GPS. It happens that in some places rock slope failures were so heavy at one spot, and took place on both sides of the road and blocked it (Fig. 4). The results of the stereographic projection show that wedge, plane and 


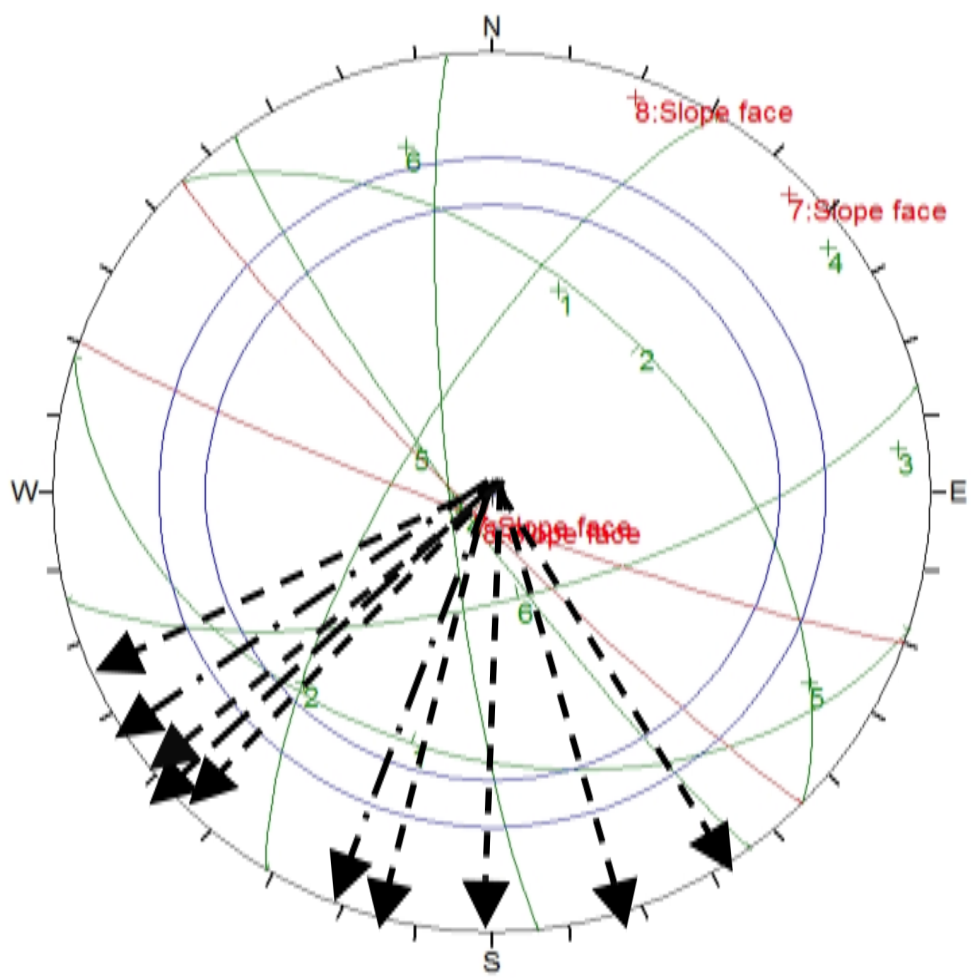

\begin{tabular}{cc}
\multicolumn{2}{c}{ Orientations } \\
ID & Dip/ Direction \\
1 & $40 / 198$ \\
2 & $51 / 045$ \\
3 & $82 / 264$ \\
4 & $84 / 234$ \\
5 & $73 / 301$ \\
6 & $70 / 166$ \\
7 & $85 / 225$ \\
8 & $85 / 200$
\end{tabular}

Equīạl Areāa

Lower Hemisphere

60 Poles

60 Entriés

Fig. (5). Stereographic projection of the joints sets along the northeastern side, show the failures directions.

toppling failures took place, (Fig. 5). Failures types and directions are given in Table $\mathbf{1}$.

\section{Plane Failures Modeling at North East Side}

The great circles of the prevailing joints sets show that the plane failures (Fig. 5) could take place, as they are close to the friction angle value at wet conditions. The great circles also indicate that a number of wedge failures are likely to take place at rainfall conditions.

Table 1. Modes of Failures of the Rock Slope North East Side

\begin{tabular}{|c|c|c|c|}
\hline $\begin{array}{c}\text { Slope } \\
\text { Face ID \# }\end{array}$ & $\begin{array}{c}\text { Failure Along } \\
\text { Joint Set \# }\end{array}$ & $\begin{array}{c}\text { Type of } \\
\text { Failure }\end{array}$ & $\begin{array}{c}\text { Direction } \\
\text { of Failure }\end{array}$ \\
\hline \hline $7 \& 8$ & 4 and 1 & Plane & $233 \& 198$ \\
\hline 8 & 2 & Toppling & 224 \\
\hline $7 \& 8$ & $\begin{array}{c}1 \& 5,6 \& 5,6 \& 3, \\
6 \& 4, \text { and } 1 \& 3\end{array}$ & Wedge & $\begin{array}{c}224,231, \\
193,160, \text { and } 180\end{array}$ \\
\hline $7 \& 8$ & $1 \& 6$ and $1 \& 4$ & $\begin{array}{c}\text { Wedge at } \\
\text { wet condition }\end{array}$ & 242 and 147 \\
\hline
\end{tabular}

The deterministic analysis was applied using the RocPlane computer program, to draw the three-dimension and side view graphs of the rock slope (Figs. 6, 7). The input data collected from the lab and field tests are as follows: slope angle $=80^{\circ}$, slope height $=8 \mathrm{~m}$, tension crack angle $=$ $85^{\circ}$, upper slope face $=35^{\circ}, \mathrm{mi}=13, \mathrm{mb}=1.15, \mathrm{~s}=0.0005$, $\mathrm{a}=0.52, U C S=7,440\left(\mathrm{t} / \mathrm{m}^{2}\right), G S I=15,22$, and 30 , unit weight $=2,760\left(\mathrm{~kg} / \mathrm{m}^{3}\right)$, rock blots $=8 \mathrm{~m}$, rock bolt angle $=$ $15^{\circ}$, rock bolt capacity $=20(\mathrm{t} / \mathrm{m})$. The percentage of water filling in the tension crack was assumed to be $100 \%$, as a conservative value, in the process of calculating the factor of safety.

\section{Wedge Failures Modeling at North East Side}

Modeling of the wedge failures (Figs. 4, 8) shows that failures are possible to take place. Graphical modeling of the joints sets indicates the possibility of many wedge failures directions to occur (Fig. 5).

The factors of safety of the wedge failures vary in a wide range (Table 2) before and without support. At seismic coefficient $=0$ after support, the factors of safety generally increase to more than 1 (Table 3 ). In case of the intersection of joints sets $1 \& 3$ and $1 \& 4$, where the factor of safety after support is $<1$, the instability could be overcomed by installing a mesh over the slope face, as the slope is relatively short, and the rock mass is highly fractured and had a low quality geotechnical properties as indicated.

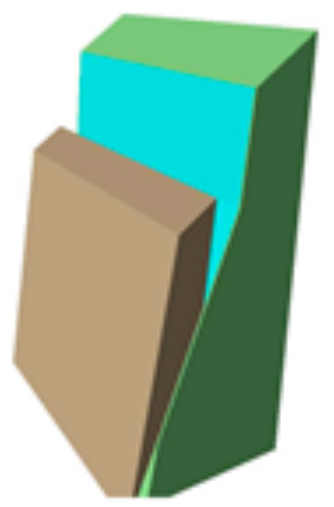

Fig. (6). The 3D plot of the plane failures north east side, similar to the actual failure shown at Fig. (4). 


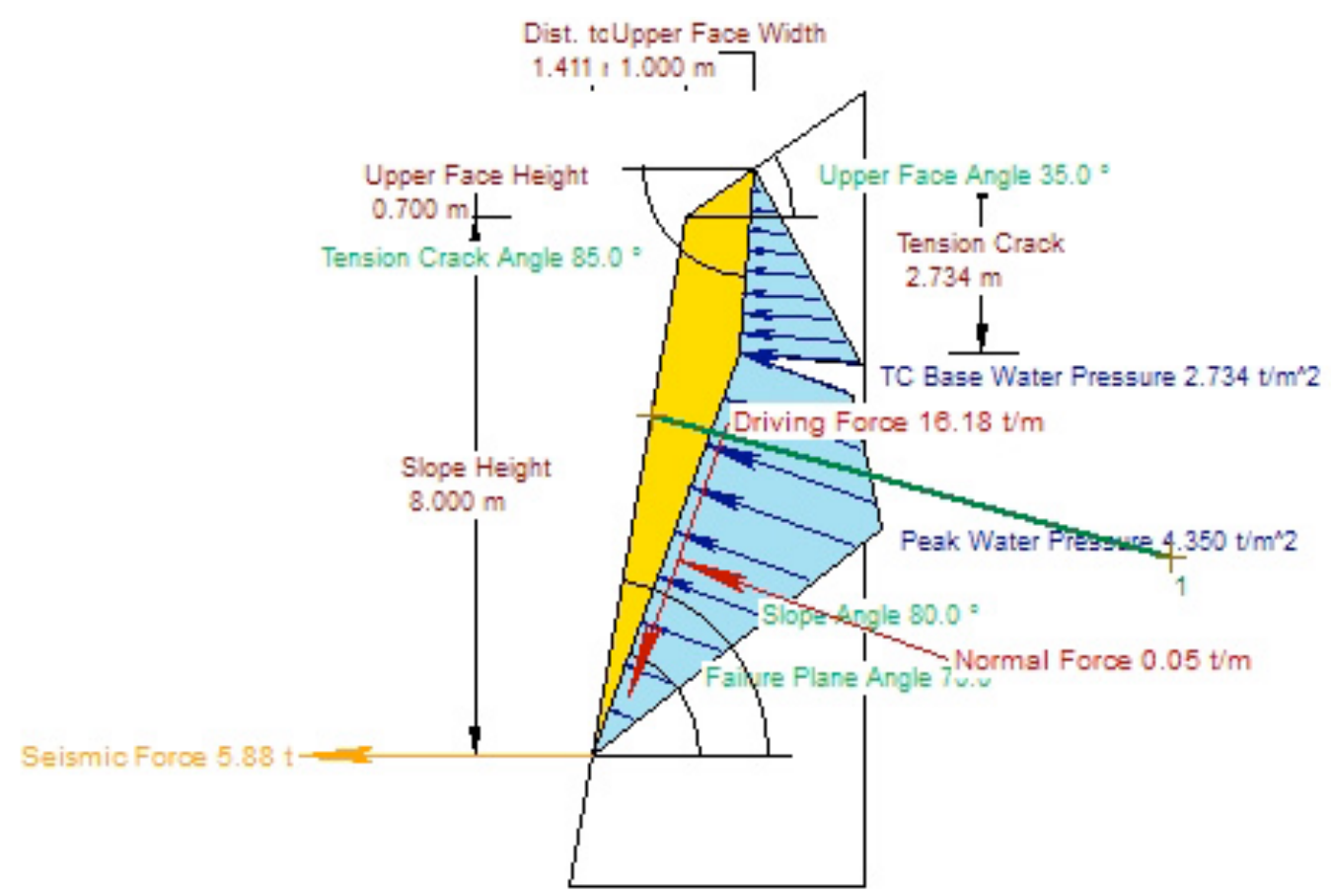

Fig. (7). A side view of the forces acting on the plane failure.

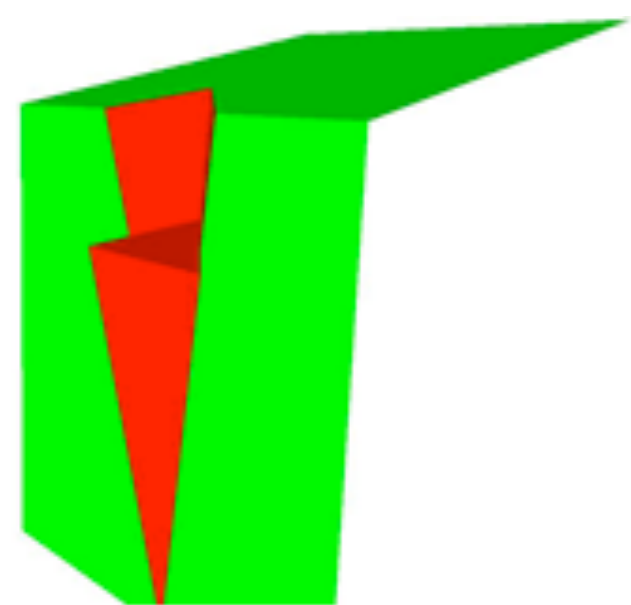

Fig. (8). The 3D plot of one of the wedge failures northeastern side, similar to the actual failures shown through Fig. (4).

\section{Plane Failures Modeling at South East Side}

The great circles of the prevailing joints sets show that the plane failures could take place (Figs. 4, 9), as the friction angle value at dry condition is close to that value at wet conditions. The plane failure and other modes of failures results are given at Table 4 and Fig (10).

The deterministic analysis was performed using the RocPlane computer program, to draw the three-dimension and side view graphs of the rock slope (Fig. 11). The input data collected from the lab and field tests are as follows: slope angle $=85^{\circ}$, slope height $=8 \mathrm{~m}$, tension crack angle $=$ $85^{\circ}$, upper slope face $=15^{\circ}, \mathrm{mi}=13, \mathrm{mb}=0.63, \mathrm{~s}=0.0008$, $\mathrm{a}=0.56, U S C=7,440\left(\mathrm{t} / \mathrm{m}^{2}\right), G S I=15,22$, and 30 , unit weight $=2,760\left(\mathrm{~kg} / \mathrm{m}^{3}\right)$, rock blots $=8 \mathrm{~m}$, rock bolt angle $=$ $15^{\circ}$, rock bolt capacity $=20(\mathrm{t} / \mathrm{m})$. Similarly, the percentage of water filling the tension crack was assumed to be $100 \%$, as a conservative value, in the process of calculating the factor of safety.

Table 2. Wedge Failures Factors of Safety Along Northeastern Rock Slopes, Before Support

\begin{tabular}{|c|c|c|c|c|c|c|c|}
\hline \multirow{3}{*}{ Slope Face ID \# 7\&8 } & \multicolumn{8}{|c|}{ Factor of Safety at Joints Sets Intersections } \\
\cline { 2 - 10 } & $\mathbf{1 \& 5}$ & $\mathbf{6 \& 5}$ & $\mathbf{6 \& 3}$ & $\mathbf{6 \& 4}$ & $\mathbf{1 \& 3}$ & $\mathbf{1 \& 6}$ Wet Condition & $\mathbf{1 \& 4}$ Wet Condition \\
\cline { 2 - 9 } & 1.02 & 0 & 0 & 0 & 0.71 & 0 & 0.36 \\
\hline
\end{tabular}

Table 3. The Factors of Safety for the Wedge Failures Along Northeastern Rock Slopes, After Support

\begin{tabular}{|c|c|c|c|c|c|c|}
\hline \multicolumn{7}{|c|}{ Factors of Safety at Joint Sets } \\
\hline $\mathbf{1 \& 5}$ & $\mathbf{6 \& 5}$ & $\mathbf{6 \& 3}$ & $\mathbf{6 \& 4}$ & $\mathbf{1 \& 3}$ & $\mathbf{1 \& 6}$ & $\mathbf{1 \& 4}$ \\
\hline \hline 1.14 & 1.59 & 1.43 & 11 & 0.84 & 2.8 & 0.6 \\
\hline
\end{tabular}

The factor of safety equals to 0 at this station at wet condition. However, after performing the support analyses by adding rock bolt of $11 \mathrm{ton} / \mathrm{m}$ capacity (Fig. 10) at seismic coefficient $=0$, the factor of safety reaches up to 1.99 .

\section{Wedge Failures Modeling at South East Side}

Graphical modeling of the joints sets (Fig. 9) indicates that many wedge failures are possible to take place (Figs. 4, 11). 


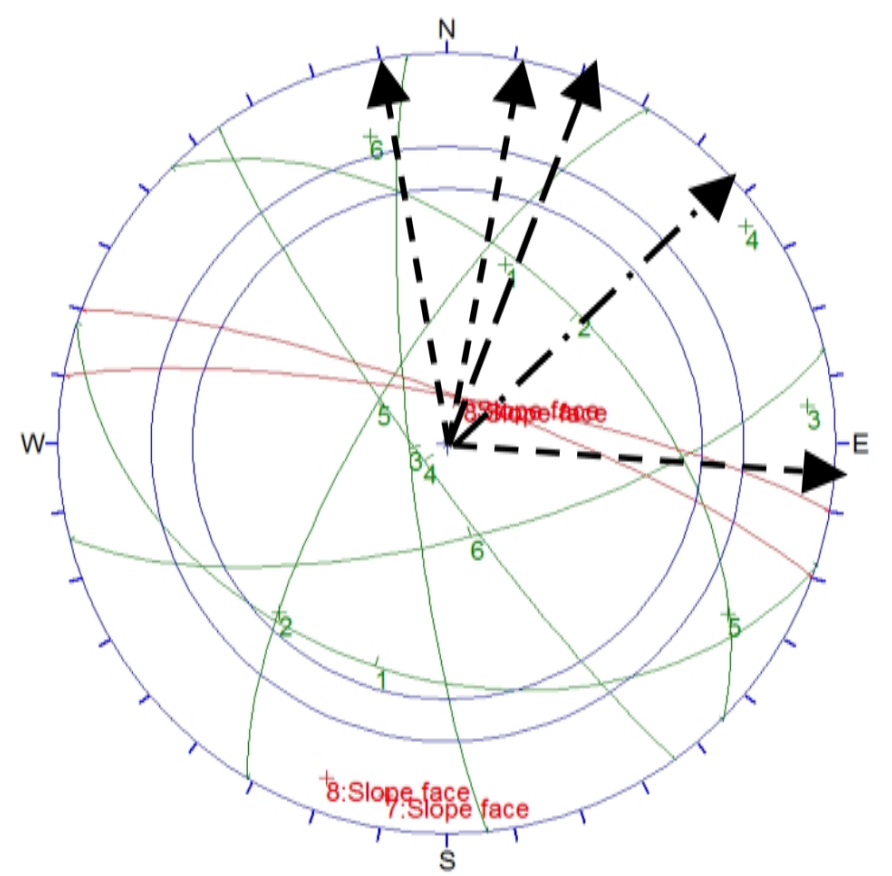

\begin{tabular}{ll}
\multicolumn{2}{c}{ Orientations } \\
ID & Dip / Direction \\
1 & $40 / 198$ \\
2 & $51 / 045$ \\
3 & $82 / 264$ \\
4 & $84 / 234$ \\
5 & $73 / 301$ \\
6 & $70 / 166$ \\
7 & $80 / 010$ \\
8 & $80 / 020$
\end{tabular}
Equal Area
Lower Hemisphere

60 Poles

60 Entries

Fig. (9). Stereographic projection of the joints sets along the southwestern side shows the failures directions.

Table 4. Modes of Failures of the Rock Slopes, South West Side

\begin{tabular}{|c|c|c|c|}
\hline $\begin{array}{c}\text { Slope } \\
\text { Face ID \# }\end{array}$ & $\begin{array}{c}\text { Failure Along } \\
\text { Joint Set \# }\end{array}$ & $\begin{array}{c}\text { Type of } \\
\text { Failure }\end{array}$ & $\begin{array}{c}\text { Direction } \\
\text { of Failure }\end{array}$ \\
\hline \hline 8 & 2 & Plane & 45 \\
\hline $7 \& 8$ & 1 & Toppling & 18 \\
\hline $7 \& 8$ & $2 \& 5$ & Wedge & 12 \\
\hline 8 & $2 \& 6$ & Wedge & 93 \\
\hline $7 \& 8$ & $2 \& 3$ & Wedge at wet condition & 348 \\
\hline
\end{tabular}

The factors of safety of the wedge failures are all less than 1 (Table 5) before and without support (Fig. 11). At seismic coefficient $(\mathrm{Sc})=0$ after scaling, the factors of safety modeling results are generally more than 1 (Fig. 4 and Table 6).

Table 5. Wedge Failures and Factors of Safety Along Rock Slopes at Southwestern Side, Before Support

\begin{tabular}{|c|c|c|}
\hline \multirow{2}{*}{ Slope Face ID \# } & Failure Along Joint Set \# & Factor of Safety \\
\cline { 3 - 3 } & & $\mathbf{S c}=\mathbf{0}$ \\
\hline \hline $7 \& 8$ & $2 \& 5$ & 0.78 \\
\hline 8 & $2 \& 6$ & 0.76 \\
\hline $7 \& 8$ & $2 \& 3$ at wet condition & 0.76 \\
\hline
\end{tabular}

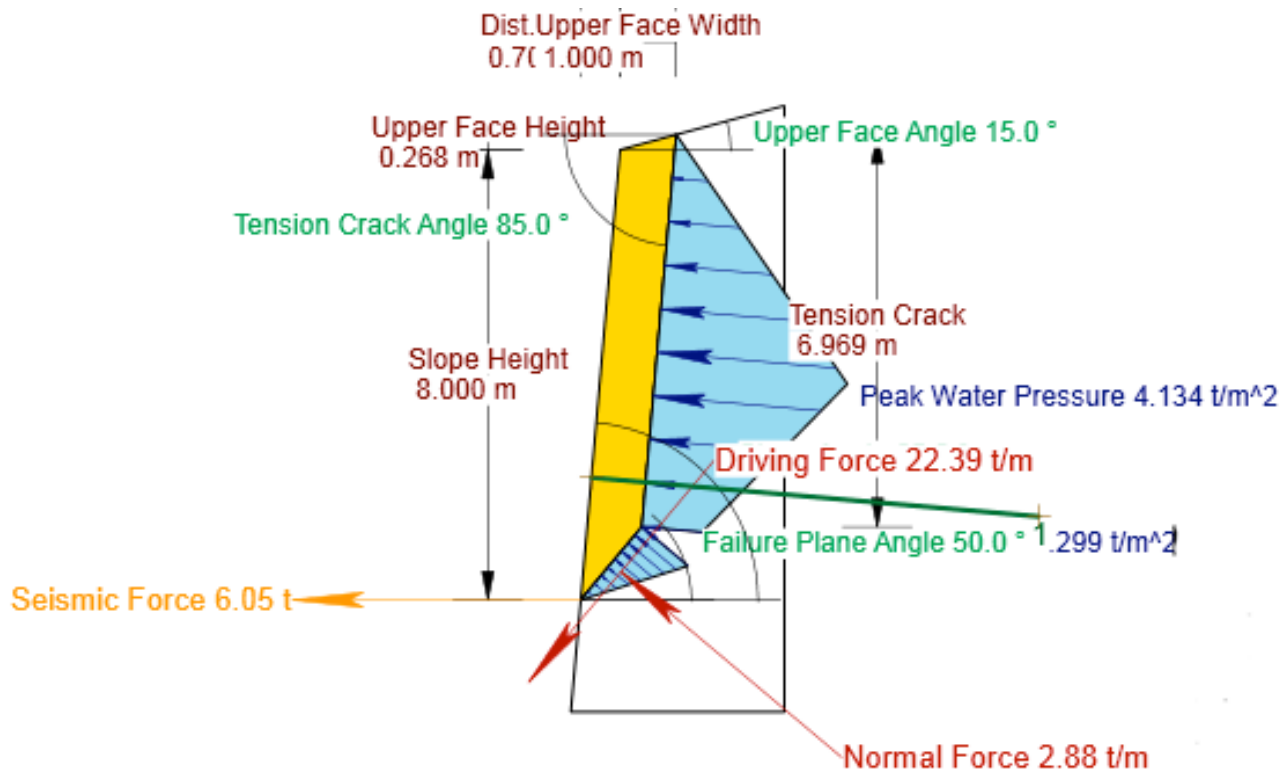

Fig. (10). A side view of the forces acting on the plane failure of rock slope at south west side. 


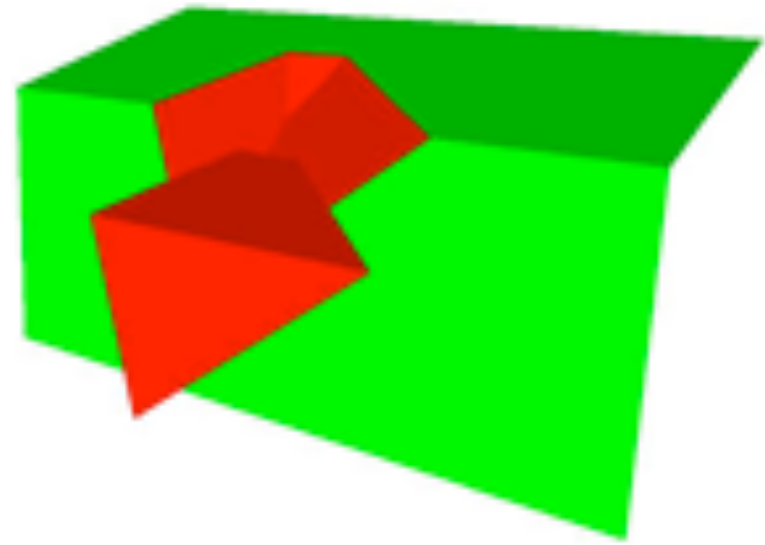

Fig. (11). The 3D plot of one of the southwestern side wedge failures, similar to the true failure shown by Fig. (4).

Table 6. The Factors of Safety for the Wedge Failure Along Rock Slopes at Southwestern Side, After Support

\begin{tabular}{|c|c|c|c|}
\hline & \multicolumn{4}{|c|}{ Rock Slope Condition } \\
\hline Joint Sets Intersections & $\mathbf{2 \& 5}$ & $\mathbf{2 \& 6}$ & $\mathbf{2 \& 3}$ \\
\hline \hline Factors of safety & 1.92 & 2.49 & 2.49 \\
\hline
\end{tabular}

\section{CONCLUSIONS}

1. The integrated techniques, including field and laboratory testing programs, $R M R$ and $G S I$ classification systems, GPS surveys, satellite data, and recent software packages of DIPS and RocFall covered the necessary data for the stability and remedial measure's requirements.

2. Rock slope failures in addition to rockfalls, and debris flows from upper steep elevations, occurring frequently along the Werka descent road, mainly during the rainy seasons harm the road.

3. The GSI classification is a valuable identification parameter to the rock mass quality, considered in taking the final support decision.

4. More slope failures could occur if the seismic coefficient increases more than 1 .
5. Rock bolts, in addition to shotcrete and slope face mesh could be the appropriate solution to stabilize this rock mass of such geotechnical quality and properties.

6. The analyses indicate that the intensity of rainfall, joints set attitudes with the slope face attitude, $J_{v}$, block size, block shape, specific gravity, and the slope geometry are the main factors causing rock slope failure and problems.

\section{CONFLICT OF INTEREST}

The author confirms that this article content has no conflict of interest.

\section{ACKNOWLEDGEMENTS}

The author expresses his gratitude to the King Abdulaziz City for Science and Technology KACST for supporting this research project under grant \# AT-29-305.

\section{REFERENCES}

[1] Bryan DF. Geologic map of the Al-Wajh quadrangle, sheet 26B, Kingdom of Saudi Arabia, Ministry of Petroleum and Mineral Resources, Deputy Ministry of Mineral Resources. Map GM 1985; 83: 27.

[2] Brown GF, Jackson RO. "The Arabian Shield" 21st International Geological Congress. Norden 1960; 9: 69-77.

[3] Blank HR. Aeromagnetic and geologic study of tertiary dikes and related structures on the Arabian margin of the Red Sea, in Red Sea Research 1970-1975. Saudi Arabian Directorate Gen Miner Resour Bull 1977; 22: 18.

[4] Moore JM. Primary and secondary faulting in the najd fault system, Kingdom of Saudi Arabia: U.S. Geological Survey Arabian Project Report 1979; 262: 22.

[5] Bieniawski ZT. Engineering rock mass classifications, New York: Wiley 1989.

[6] Hoek E. Strength of rock and rock masses, ISRM News J 1994; 2: 4-16.

[7] Hoek E, Kaiser PK, Bawden WF. Support of underground excavations in hard rock. Rotterdam: Balkema 1995.

[8] Hoek E. Applied Rock Engineering. Internet edition 2007.

[9] Hoek E, Bray JW. Rock slope engineering, $3^{\text {rd }}$ ed. Institute of Mining and Metallurgy 1981; p. 358.

[10] Rocscience DIPS 2013; 6: Getting started user's guide. 